\title{
O PLANEJAMENTO DO ENSINO EM UM PROGRAMA DE DESENVOLVIMENTO PROFISSIONAL DOCENTE
}

\author{
Anne L. Scarinci" \\ Universidade de São Paulo (USP) \\ Jesuína L. A. Pacca"* \\ Universidade de São Paulo (USP)
}

RESUMO: Um grande problema a ser enfrentado é como concretizar ações de formação docente que superem a dicotomia teoria-prática. Em um programa de desenvolvimento profissional docente com tais intenções, analisamos como o formador conduziu o aprendizado sobre o planejamento e também o modo como foram concretizados os objetivos específicos e gerais do programa. Observamos que o tema surgiu de uma necessidade expressa pelos participantes, em relato sobre sua prática, e que a condução da discussão pelo formador pode ser descrita em quatro fases, desde a abertura de espaço para o surgimento do problema desencadeador, até um desfecho que sintetiza o conhecimento alcançado. O formador trabalhou a partir da prática docente dos professores participantes, iniciou os episódios de ensino pela atitude de ouvir o professor e manteve ações coerentes com a prática pedagógica desejada. Em síntese, a pesquisa permitiu evidenciar traços significativos do desenvolvimento profissional, observáveis em atuações específicas, pertinentes e apropriadas do professor frente a situações da sala de aula.

Palavras-Chave: Desenvolvimento profissional docente. Formação continuada. Construtivismo. Reflexão sobre a prática.

\footnotetext{
http://dx.doi.org/10.1590/0102-4698120707

* Doutora em Educação pela Universidade de São Paulo (USP) e Professora do Instituto de Física da Universidade de São Paulo (USP). E-mail: anne@if.usp.br

* * Doutora em Educação pela Universidade de São Paulo (USP) e Professora Associada no Instituto de Física da Universidade de São Paulo (USP). Email: jepacca@if.usp.br
} 


\section{THE TEACHING PLAN IN A TEACHER EDUCATION PROGRAM}

ABSTRACT: A considerable problem to be faced by teacher development programs is how to develop actions in teacher education, which overcome the dichotomy theory-practice. In a teacher's professional development program with such intentions, we analyzed how the educator conducted learning on the content about lesson planning, relating his actions to how the more general objectives of the program were met. We observed that the emergence of a theme came from an expressed need formulated by the teacher through an account of her practice. The conduction of the discussion, by the educator, was described in four phases, from phase 1 - opening space for the appearance of the problem, until phase 4 - a closure that synthesized the knowledge acquired. The educator departed from the participant teachers' practice, initiated the episodes with the attitude of listening to the teacher and maintained actions coherent with the desired pedagogical practice that he wanted to teach. The research disclosed meaningful traces of professional development, located in specific, pertinent and appropriate performances of the teacher, before classroom situations. Keywords: Teacher professional development. Teacher education. Constructivism. Reflection about practice.

\section{INTRODUĈ̣̃O}

O processo pedagógico de planejar refere-se à delimitação de um eixo para o planejamento (um objetivo geral a ser alcançado), à escolha de atividades para direcionar o aprendizado, com a determinação dos objetivos gerais e específicos, e à localização dessas atividades numa sequência pedagógica coerente e orientada para a aprendizagem (PACCA, 1992).

Professores em atuação já têm algum conhecimento sobre o processo de planejamento do ensino. No entanto, nota-se que, comumente, os professores conseguem elencar uma lista de conteúdos a serem ensinados, porém têm dificuldades em designar atividades para o ensino daqueles conteúdos e objetivos para o tema em estudo que produzam coesão entre as atividades. Além disso, geralmente há pouca clareza sobre as razões da escolha de uma determinada sequência pedagógica (fundamentadas em uma determinada concepção de ensino). Assim, quando se pede ao professor que elabore o seu plano de ensino, usualmente, o que se obtém é algo muito parecido com os índices de livros didáticos e organizações de conteúdos em uma lógica diferente daquela que tornaria o aprendizado mais significativo. Ou seja, o plano de ensino pouco reflete as necessidades dos aprendizes em termos da construção do conhecimento científico. 
Nas escolas públicas brasileiras, pede-se que o professor entregue um plano de ensino para suas turmas no início de cada ano letivo. Esse processo, infelizmente, é entendido por muitos professores como uma exigência burocrática e com pouca utilidade prática, visto que, tanto não há relatos de uso desses planos pela coordenação escolar, quanto o próprio professor pouco utiliza efetivamente o seu plano para orientar suas ações em sala de aula, como um instrumento imprescindível para atingir determinados objetivos. Os objetivos de ensino são confundidos com os conteúdos - e o "plano" que o professor efetivamente segue é o sumário do livro didático. Como consequência dessa falta de habilidade em planejamento, as aulas ficam truncadas e sem um eixo de construção conceitual que confira alguma unidade às várias atividades e que seja capaz de orientar as ações docentes no diálogo com o aluno (SCARINCI e PACCA, 2009), prejudicando enormemente o aprendizado.

Durante alguns anos, tivemos a oportunidade de acompanhar um programa de formação de professores que, dentre várias competências, habilidades e atitudes que desenvolvia nos participantes, trabalhava de uma forma particular sobre o planejamento do ensino. Os planos de ensino dos professores participantes do programa, bem como seus relatos dos resultados de aprendizagem, adquiriam características marcadamente diferentes dos da maioria dos professores com quem mantínhamos contato. A partir dessa observação, a pergunta que inspirou este trabalho foi - como se ensina a planejar? Quais são os obstáculos na aprendizagem do planejamento didático e que estratégias de ensino o formador pode escolher para trabalhar esse tema?

\section{O DESENVOLVIMENTO PROFISSIONAL DO PROFESSOR}

Nossa incursão pela literatura leva-nos a considerar alguns autores que se ocupam da tarefa de formar o professor e que, a nosso ver, mostram bastante convergência entre si e auxiliam na compreensão do que entendemos por esse fenômeno.

A prática docente, por ser constituída de uma série de ações rotineiras, é uma prática habitual, conforme analisam Stenhouse (1984), Schön (2000), e outros autores. Uma característica importante da ação habitual é que ela consegue ser automática (e por isso mais rápida e ágil) e requer pouca ou nenhuma reflexão para ser realizada.

Conforme aumenta a facilidade na ação, a mediação verbal na execução da tarefa usualmente desaparece. $\mathrm{Na}$ verdade, a própria habilidade para verbalizar o conhecimento presente na ação pode ser perdida. (Anderson, 1990,p. 227 tradução nossa) 
Essa característica intrínseca das práticas habituais, por um lado, representa uma grande vantagem, quando garante a execução de todas as pequenas ações necessárias, aliviando a atenção do ator em relação a cada uma delas e seus detalhes e deixando-o à vontade para ocupar-se do quadro mais complexo ou de novidades que apareçam. Por outro lado, quando queremos aperfeiçoar nossa prática ou compreender por que ela produz alguns resultados indesejados, precisamos recuperar a capacidade de descrição do que fazemos e dos seus porquês - os critérios implícitos, conforme Stenhouse (1984).

Essa é uma das recomendações de vários autores - a começar por Schön (2000) - sobre a formação docente: deve possibilitar espaço para que o professor possa, mediado pelo formador, pelos pares e pelo referencial teórico em pauta, refletir sobre sua prática.

A reflexão, especialmente em relação aos objetivos das ações educativas, é bastante apropriada porque, ainda como defende Schön (2000), o ensino não é uma simples aplicação técnica de um conhecimento, do que decorre que não há uma resposta nos livros para vários dos problemas enfrentados na sala de aula.

O tratamento da maioria dos dilemas que surgem na prática docente deve levar em conta o que, naquele contexto de ocorrência específica, configura-se como mais relevante do ponto de vista da educação (CONTRERAS, 2002). Tal ação transcende o que pode ser prescrito por técnicas derivadas da pesquisa aplicada e requer do professor o uso de recursos criativos, da intuição ou da improvisação, em vista de objetivos de ensino além dos triviais, de conteúdo. É nesse quesito que se faz necessária a politização do professor, pois tais objetivos são escolhidos e levados a cabo pelo docente em interação com seus alunos em sala de aula, muitas vezes independentemente das decisões de instâncias normativas.

Por exemplo, esquecer-se de trazer a borracha e ter que pedi-la emprestada interrompendo uma explicação é um ato de indisciplina de natureza diferente da de "colar na prova". O que o professor vai enfatizar, a partir desse ocorrido, pode ser esquecimento do material escolar obrigatório, a interrupção da aula, ou algo diverso, que dependerá da relação que ele tem com os alunos, do histórico da classe e de características daquele aluno que cometeu a transgressão. Um conjunto de normas genéricas sobre "como tratar a indisciplina" não conseguiria dar conta de todas essas variáveis e prever, para cada contexto particular, o encaminhamento mais adequado - do ponto de vista educativo, enfatizamos, pois é em cada um desses pequenos conflitos que se realiza a tão falada educação para a cidadania. 
De maneira análoga, cada dilema que o professor traz ao grupo de formação é levado em conta a partir de seu contexto específico. Isso exige do programa de formação uma negociação através de princípios gerais da atuação docente, sem traduzi-los em regras ou estratégias delimitadas e genéricas. Essa competência na atuação do formador será exemplificada na seção de análise deste trabalho.

Embora a reflexão seja um atributo humano, o pensamento reflexivo sistemático, no sentido de fazer da prática docente um campo de reflexão teórica como estruturadora da ação, é uma capacidade que pode ser desenvolvida, mas que não desabrocha espontaneamente (ALARCÃO, 1996). Justifica-se, por conseguinte, que a reflexão se coloque como um objetivo explícito do programa de formação.

Segundo enunciado de Vieira (1994), podem ser estratégias de formação reflexiva o enfoque no sujeito e nos processos de formação, a problematização do saber e da experiência, a integração teoriaprática e a introspecção metacognitiva. Zeichner (1992) também defende a importância de que o professor proceda, junto ao coletivo docente, como pesquisador de sua prática, e propõe uma formação docente que se utilize de problemas desencadeadores, que possam advir da própria prática e a ela se dirigir. Essa ideia é interessante também do ponto de vista de favorecer um aprendizado situado, que mantenha o vinculo com as necessidades dos professores (expressas e reais) e com os conhecimentos que eles já possuem. De fato, Pimenta (2002) analisa que uma formação consegue ser muito mais bem sucedida quando parte dos saberes iniciais dos professores.

Professores em serviço já detêm um conjunto de saberes que, minimamente, funcionam no sentido de prover sua sobrevivência na profissão. Dentre esses saberes estão formas de explicar o conteúdo, de manter a atenção da classe, de motivar os alunos, de montar uma avaliação escrita, de responder perguntas, etc. Cada uma dessas competências não se manifesta isoladamente, mas faz parte de um todo, de uma estrutura de ação que apresenta certa coerência interna, em termos de uma concepção de ensino e aprendizagem (embora essa concepção nem sempre esteja em nível consciente).

As práticas de um professor podem não ser todas absolutamente coerentes com uma determinada concepção de ensino e aprendizagem, mas, quando esse professor é adepto de uma determinada concepção de ensino, essencialmente suas ações estarão insertas naquele paradigma. Agir consistentemente dentro de uma visão de mundo simplifica o planejamento e a interpretação da realidade, porque cada passo partilha de um mesmo contexto implícito. Desse modo, 
a previsibilidade sobre as interações com os alunos é grande, e um plano de curso consegue efetivamente servir de guia durante a realização das aulas. Além disso, a capacidade de improvisação do professor é alta. Ele se sente confortável na aula, porque sabe o que fažer quando surgem dificuldades de aprendizado que não haviam sido previstas.

O desenvolvimento profissional do professor, compreendido de forma ampla, trata de todo aprendizado - ligado a conhecimentos sobre o ensino, atitudes, relações interpessoais e competências relativas ao processo pedagógico - adquirido ao longo da vida (SILVA, 2002). Segundo Grundy e Robison (2004), o aprendizado no âmbito do desenvolvimento profissional pode ser classificado a partir de três propósitos interligados: a extensão (introdução de novos conhecimentos ou capacidades ao repertório), o crescimento (desenvolvimento de maiores níveis de especialização) e a renovação (transformação do conhecimento e/ou da prática).

A renovação das práticas de sala de aula, especialmente quando tal mudança se embasa em uma concepção diferente de ensino e aprendizagem e de ciência, envolve a alteração de toda a estrutura de pensamento e ação, e não somente de um subconjunto de práticas, como por exemplo, de explicação ou respostas a dúvidas dos alunos. Muito raramente tal propósito é conseguido sem o apoio de um grupo e de um elemento assimétrico - um formador - que possa auxiliar o profissional a refletir sobre sua prática e readequá-la às novas concepções.

Esse é o ponto de partida da maioria dos programas que atuam no âmbito do desenvolvimento profissional de professores de física: os professores frequentemente trazem uma visão empíricoindutivista de ciência, bastante coerente a uma visão positivista e transmissiva de ensino (BRICKHOUSE, 1989); os formadores, por outro lado, querem ensinar uma pedagogia sócio-interacionista ou construtivista, coerente com uma epistemologia construtivista da ciência (MALDANER, 2006; BEJARANO; CARVALHO, 2004; CAMARGO; NARDI, 2005, dentre outros).

Especialmente nessas situações, o programa de formação deve ser capaz de assessorar o professor durante esse período de modificação de suas práticas pedagógicas, não somente fornecendolhe novas possibilidades de ações planejadas, estratégias de ensino e atividades, mas também o amparando quando precisa interpretar comportamentos ou resultados imprevistos dos alunos, quando quer compreender uma aula que "desandou", ou mesmo quando precisa compreender e generalizar um resultado positivo, para poder usá-lo em outras ocasiões - esse foi um resultado bastante contundente a 
que chegamos em uma investigação com professores que desejavam modificar suas práticas (SCARINCI, 2006). Ou seja, o programa de formação que tem metas de mudanças das práticas docentes deve manter-se próximo ao professor durante a concretização da prática nova. É esse o espírito que queremos dar ao termo "programa de desenvolvimento profissional", já cunhado pela literatura internacional, mas que nem sempre mantém uma relação biunívoca com a ideia da superação da teoria deficitária (AVALOS, 2004) e com o embasamento em estratégias que valorizem o profissionalismo do professor através da prática fundamentada em evidências e em pesquisas feitas pelos professores e com eles (DAY; SACHS, 2004).

Nessa abordagem, uma das estratégias fundamentais é nutrir um diálogo efetivo com o professor, o que auxilia na construção de uma identidade profissional mais sólida e age na direção da conscientização sobre suas ações e seus motivos e consequências, conferindo-lhe maior autonomia. "Quanto mais me assumo como estou sendo e percebo a ou as razões de ser de porque estou sendo assim, mais me torno capaz de mudar, de promover-me, do estado de curiosidade ingênua para o de curiosidade epistemológica.” (FREIRE, 1996, p.44)

A defesa da necessidade de superação da dicotomia teoriaprática é apontada por muitos estudiosos da educação há algumas décadas (FÁVERO, 1993) e vem ocupando cada vez mais o foco das discussões sobre a formação docente.

Apesar de a nova legislação sobre os cursos de licenciatura (BRASIL, 2002) dar grande ênfase a essa relação, os cursos de formação inicial ainda não conseguiram relacionar e equilibrar adequadamente os componentes teóricos e práticos do currículo (SAVIANI, 2009) e a universidade tem sido acusada de academicismo e de falta de atenção ao trabalho real do professor (LÜDKE; BOING, 2012).

Em discurso proferido em 2011 em São Paulo ${ }^{1}$, António Nóvoa ressalta a necessidade de que as ações de formação docente tomem a prática real do professor como elemento estruturante de sua formação, invertendo a lógica atual, de caráter normativo e orientada por referenciais externos à atividade docente, para ações que priorizem a análise da prática e da formação vigentes.

Um grande problema que os formadores têm enfrentado é de como concretizar tais ideias, estruturando-as em ações efetivas de formação inicial e desenvolvimento profissional. Um trabalho de PACCA (1992) destaca o plano de ensino do professor como instrumento fundamental para sua atuação, e a reflexão orientada sobre o planejamento como uma forma profícua de promover o 
desenvolvimento profissional, pois por meio dele consegue-se partir da prática real (não prescrita) do professor e dos conhecimentos e das competências que ele possui. Transformar ideias pedagógicas em ações não parece ser trivial - queremos, portanto, investigar ações derivadas dessas propostas de formação, no intuito de nos dirigirmos a novas rotinas de pensamento e ação, mais coerentes com os discursos. Para isso, desenvolvemos pesquisas empíricas das quais esta faz parte - buscando analisar programas e ações de formação com respeito a essas ideias.

\section{OBJETIVO}

Nosso problema maior é o de investigar ações de formação docente coerentes com uma superação da dicotomia teoriaprática, que levem em conta os saberes e os pontos de partida dos professores. Neste trabalho, fizemos uma aproximação a essa questão, por meio de um estudo de caso ligado a um determinado programa de formação. Esse programa tinha objetivos amplos, de forma que fizemos um recorte ligado ao ensino do planejamento: analisamos como a competência de planejar é trabalhada pelos formadores do programa. O processo de planejamento do ensino é entendido como um processo de pensar o ensino e a aprendizagem, seus objetivos e suas condições de concretização, levando-se em conta tanto o que se pretende como formação cidadã, quanto o ponto de partida para a realização da prática docente. Nas palavras de Fusari (1990, p.45), "o planejamento, nessa perspectiva é, acima de tudo, uma atitude crítica do educador diante de seu trabalho docente." Fusari (op.cit.) ainda ressalta a diferença entre o planejamento do ensino e os planos de ensino, comenta sobre os tipos de plano e avalia como o pensamento tecnicista influiu negativamente para que o planejamento do ensino realizado atualmente pelos professores se tornasse uma ação meramente burocrática e que não atende à sua importantíssima função educativa para o aluno e de servir como valioso instrumento de reflexão para o professor.

Esta pesquisa pretende investigar as ações do formador no trabalho com o planejamento do ensino. Partindo da realidade constatada, quisemos analisar o que fez o formador para proporcionar o aprendizado de como realizar planos de ensino e, sobretudo, de como realizar o processo reflexivo do planejamento. Como o programa que acompanhamos partia da prática real do professor, nossa produção de dados enfocou a emergência de uma questão da prática docente, 
as formas de condução das reflexões que tiveram os participantes, o desfecho e o modo como o formador concretizou os objetivos específicos e gerais do programa de formação (modificar a prática docente e a concepção de ensino do professor, desenvolver a autonomia docente e o expertise no ensino de física), através dos diálogos contextualizados estabelecidos durante os encontros do programa.

A escolha do programa de desenvolvimento profissional a ser estudado para este trabalho teve como critério os resultados alcancados, em termos de modificação efetiva nas práticas docentes dos participantes. Neste texto não explicitamos como foi o processo para essa escolha, mas essa informação pode ser encontrada em Scarinci (2006) e Scarinci (2010).

\section{PRODUCְÃO DE DADOS E METODOLOGIA}

Nossa produção e análise dos dados foram típicas da pesquisa qualitativa e, embora não pretenda caracterizar-se como pesquisa etnográfica strictu sensu, contou com vários elementos etnográficos, conforme Lüdke e André (1986) - dentre eles a inserção prolongada na comunidade estudada e a inserção de grande quantidade de dados primários no relato da investigação.

O programa de formação se desenvolveu em uma instituição de ensino superior de São Paulo e é apoiado pela FAPESP, dentro do Programa de Melhoria do Ensino Público. Participaram cerca de dez professores de física de escolas públicas estaduais paulistas (o número varia conforme o semestre; tomamos dados de 5 semestres), o formador e dois formadores auxiliares (monitores). O tema de ensino discutido no período considerado foi o da eletricidade. O programa tem orientação construtivista.

Os professores que participavam do programa eram, inicialmente, professores considerados "típicos" da rede pública, ou seja, não possuíam uma relação prévia com a universidade (como alunos de pós-graduação strictu sensu) e a maioria não possuía sequer a graduação em física (dada a enorme carência desses especialistas no país).O quesito para participação era ter a disponibilidade de tempo (especialmente para a reunião semanal) e o interesse em participar de um grupo que tem como objetivo a transformação das práticas docentes. Havia professores participando do programa há vários anos e outros novatos; havia também professores com diversos períodos de experiência em sala de aula.

As atividades do grupo consistiam em reuniões semanais com 6 horas de duração (das 14 às 20 horas), mais atividades feitas 
pelos participantes individualmente e compartilhadas por email ou nas próprias reuniões (incluindo a aplicação do plano de ensino em uma turma da escola pública em que lecionavam) - totalizando uma dedicação de cerca de 20 horas semanais. As reuniões, que aconteciam na universidade, compunham-se por dois momentos. As primeiras 3 horas eram orquestradas pelo formador, um professor universitário, e o conteúdo versava sobre a prática dos professores (seus relatos de aulas ou seus planejamentos de ensino, suas dúvidas, conceituais ou práticas, ocorrências típicas ou atípicas nas escolas que pudessem interferir no seu trabalho docente). Tipicamente, os encontros, nessa parte das reuniões, começavam com um relato do professor, que apresentava ao grupo uma situação-problema.

$\mathrm{Na}$ segunda parte das reuniões semanais, os professores trabalhavam em grupos com auxílio (se necessário) dos monitores, sem a presença do formador sênior. As atividades dependiam do que havia sido discutido na primeira parte da reunião e que havia se configurado como uma necessidade de aprofundamento: estudos sobre questões de física, montagens de aparatos e planejamento de atividades experimentais, discussões com reflexões por escrito sobre algum tema específico do ensino (como avaliação, tipos de estratégias de ensino, etc.). Essa parte não foi nosso objeto de análise neste trabalho, mas descrições mais pormenorizadas podem ser encontradas em Silva (2009) e SCARINCI (2010).

As reuniões do grupo de formação foram gravadas em áudio e transcritas. Os dados foram escolhidos com base nas transcrições, acompanhadas das notas de campo dos pesquisadores. $\mathrm{Na}$ apresentação dos dados, designaremos os professores participantes por conjuntos de três letras (PLA, EDU, SIL), os monitores por duas letras (NA, FE) e o formador pela letra F.

As situações de ensino são contextualizadas nos planejamentos de cada professor e nos relatos das suas aulas: a partir de um relato ou de uma tarefa de planejamento, o formador escolhe e desenvolve algum dos seus objetivos de ensino. Por conseguinte, podemos dividir as reuniões em episódios - cada episódio completo começa com um depoimento, de um dos professores participantes, acompanhado da discussão com os outros participantes, e termina em um fechamento, pelo formador, que interpreta o problema relatado, procurando auxiliar o professor a encaminhar soluções (uma transcrição completa de uma reunião encontra-se em SCARINCI, 2010, p. 40-56).

Para a questão investigativa proposta neste trabalho, a escolha dos episódios que comporiam nossa análise se deu em função do desfecho do episódio, em termos do aprendizado principal proporcionado 
ao professor e enfocado pelo formador na sua fala de desfecho. Nessa dimensão de análise - segundo o conteúdo dos diálogos classificamos os episódios em três categorias maiores - planejar, conduzir a aprendizagem e avaliar os resultados (a última categoria com algumas subdivisões), como ilustra o Quadro 1.

\section{QUADRO 1}

\section{Classificação analítica dos episódios de formação}

I - Classificação segundo o conteúdo dos diálogos: as ações do professor em foco:

1. Planejar

2. Conduzir a aprendizagem

3. Avaliar os resultados

3.1. O planejamento

a) Incluir as condições socioculturais dos educandos

b) Explorar o conhecimento de física com o rigor possível

3.2. A aprendizagem

a) Explorar a natureza dialógica da construção do conhecimento científico

b) Assumir um posicionamento político-pedagógico

II - Classificação quanto aos saberes e ações transversais

III - Classificação quanto às competências e habilidades do formador

Fonte: Scarinci, 2010.

Para este trabalho, utilizamos os dados classificados dentro da categoria I - 1: planejar o ensino. Dentre todos os episódios incluídos nessa categoria, tomamos os que consideramos mais típicos do programa, conforme ocorrência de uma fase introdutória do episódio (quando o problema surge e é descrito em detalhes), uma fase interpretativa (quando se procuram os determinantes implícitos da situação) e uma fase conclusiva (que trata das possibilidades de ação do professor, dentro dos determinantes contextuais analisados nas fases anteriores).

\section{ANÁLISE}

O programa desenvolvia-se na forma de diálogos, procurando, sempre que possível, tomar como ponto de partida a prática docente de algum dos participantes. Como essa forma de condução do ensino adotada pelo programa será determinante para nossas conclusões, apresentamos, inicialmente, um episódio mais completo, a partir do qual analisamos as ações e habilidades mobilizadas pelo formador. Em seguida, complementaremos a análise com trechos de outros episódios, conforme exemplos adicionais sejam requeridos e oportunos. 
O episódio a seguir começou com a atividade "conte a sua aula", em que o professor relata descontentamento com uma de suas aulas, pois a achou sem significado dentro do seu plano de ensino. Tomando o conceito da "reflexão sobre a ação" de Schön (2000), o problema manifestado pelo professor, nas palavras dele próprio, foi "não dei a aula que eu queria". Durante a discussão, vemos como o formador desconstrói esse problema aparente e constrói o problema de fato que é a falta de clareza do professor sobre os usos e objetivos da aula de resolução de exercícios que ele havia incluído em seu plano de aula.

PLA - Eu dei aula, mas não dei o que eu queria, porque eu tinha passado exercícios, eu passei as formulinhas, né. Fórmula da resistência... (...) então na outra aula eles queriam que corrigisse, que eu tinha marcado prova. Aí eu corrigi os exercícios e dei a prova, só de formulinhas. E eu marquei com eles/

$\mathrm{F}-\mathrm{O}$ que quer dizer que você corrigiu exercícios?

PLA - Ah, eles têm dúvida, "ah, eu não consegui fazer esse”, eu peguei exercícios de vestibular, assim.

$\mathrm{F}$ - Mas o que que é corrigir exercício?

PLA - Ah, é corrigir na lousa...

F - Não, "corrigir na lousa" não, corrigir é corrigir alguma coisa.

PLA - ... Não, não é corrigir; é fazer ${ }^{2}$. (!)

F - Pois é... Então... (!)

PLA - Alguns, até perguntam, “ah, eu não consegui, eu estou travado aqui”, aí.../

F - Mas isso não se chama corrigir também. Não é? O que você fez, afinal de contas? Descreve o que você fez.

PLA - Então, alguns eu orientei como fazia, e outros que não tinham a menor ideia eu fiz o exercício. Na lousa.

NA - Você fez na lousa e eles copiaram.

F - Então, isso não se chama corrigir. Quer dizer, você resolveu o problema na lousa, entendeu? (...) Então você resolveu o problema na lousa; o que você queria com essa atividade? Porque isso foi uma atividade, né? Fazia parte do teu planejamento?

PLA - não.

F - Não, não fazia. E aí ela entrou. Então o que você queria com ela? Vamos ver se você consegue dar um significado.

PLA - Eu queria fazer eles perceberem que era possível fazer, e que era simples... resolver os problemas.

F - Era simples? (PLA - Éé...) Pra quem? Para a professora. Para a professora. [pausa] Sabe, a gente faz muita coisa que a gente não percebe o que está fazendo, né, a gente vai usando o nosso esquema tradicional, "ah, eu corrigi a prova". Corrigir você corrigiu quando você pegou a prova de cada um, marcou, riscou, deu nota, você corrigiu. (...) O que você foi fazer, você não foi corrigir a prova. Isso se chama outra coisa. Não é? E aí, outra coisa, tudo bem. Ela pode caber no planejamento. Eu estou te cobrando a mesma coisa que eu te cobrei da outra 
vez, (que depois nós vamos falar também.): O que essa atividade tem a ver com o meu planejamento? (...)Então tem a... essa coisa, das atividades, que a gente costumeiramente faz, que a gente viveu assim, aprendeu assim, e a gente agora precisa dar outro significado pra ela, e entender - o que é que isso tem a ver com o meu planejamento? De onde eu venho, pra onde eu vou, onde que eu quero chegar, e como é que isso está contribuindo? (...)

EDU - E se a gente verificar que ... que não atingiu o objetivo?(...)

F - Não, mas aí é que está, você tem que ver por que você acha aquilo importante e o que o teu objetivo na verdade está exigindo. O que é que ele exige, e se isso tem ligação. Todo esse processo de reflexão é que vai começar a construir a nossa postura de profissional. (...) "eu achei que [esse experimento/atividade] é bonito, mas será que é oportuno? Será que está no lugar certo?”

(...)

PLA - É [riso]. Mas tem essa outra turma, que eu não corrijo os exercícios/ eu não faço os exercícios pra eles, eu espero que eles façam e, se tem dúvida em algum, eu vou lá e vejo qual é a dúvida, (...) Mas tem duas alunas que ficam desesperadas. Elas acham que tem que corrigir tudo. E elas fazem com que eu me sinta culpada de não corrigir tudo. (...)

F - Agora veja uma coisa, PLA. Olha, quando a gente põe uma coisa na lousa, a gente dá assim, um modelo, né...

PLA - É, aí não adianta nada, eles copiam...

F - Não, não é que não adianta nada, adianta também. Não sei se adianta para o que você quer. (...) Então, mostrar os modelos, os protótipos e tal, também é considerado como uma atividade interessante. Mas será que a gente faz isso com consciência de que faz isso? Será que eu queria isso no planejamento ou não? Então essa que é a questão importante.

PLA - Sempre que eu passo a resolução, que eu resolvo na lousa, eu não me sinto muito bem. Porque eu sei que aquilo eles vão copiar, e pode até não fazer sentido, ele pode até repetir aquela sequência, sem saber o que está fazendo, não é isso o que eu quero.

KAP - Mesmo porque [pra eles fica a ideia que] aqueles exercícios devem estar resolvidos daquele jeito. Se mudar alguma coisinha... (...)

NA-Quandoeuestavanoprimeiroano[doEnsinoMédio], queeuestavaaprendendo física pela primeira vez, eu me perdia pra caramba com as variáveis lá da mecânica. E eu lembro que o professor fez uma aula de exercícios, e ele colocava na lousa assim, ele usava a lousa inteira. Então "que é que você quer saber, a aceleração. Então, qual é a fórmula?" Então ele colocava a fórmula. "Ah, mas a gente precisa da velocidade, a gente não tem a velocidade." Então ele abria outro quadrado depois pra calcular a velocidade. "Qual é a fórmula da velocidade? Essa." (...) E depois ele voltava, pra resolver... Foi um modelo, que ele deu. Mas foi tão organizador pros meus pensamentos!

PLA - Ah! Então deu certo pra você! (...)

F - Então o negócio é isso aí, é ressignificar as atividades que a gente faz já por tradição, né. É dar outro sentido àquilo, e sempre a preocupação é olhar, como é que isso está ligado ao planejamento. É isso que eu venho desenvolvendo? É pra onde que eu quero ir? Essa que é a questão. 
Muitas das rotinas que o professor adota em suas aulas são vistas como "naturais" da sala de aula. Uma aula de correção de exercícios, uma prova escrita individual ao final do bimestre, uma cópia de definições da lousa...

Raramente, durante a realização dessas atividades, o professor tem a possibilidade de refletir sobre os motivos que fundamentam aquelas rotinas. Trabalhos que analisam a teoria de Schön no contexto docente questionam se seria possível uma reflexão na ação, quando essa ação acontece no contexto da sala de aula, pois as ações são várias, simultâneas e devem ser imediatas (GURIDI, 2007).

No entanto, maior talvez que esse obstáculo seja que não paremos para refletir sobre o que é visto como trivial. Como no Mito da Caverna (PLATÃO, 2006), em que as sombras não são questionadas porque sempre estiveram ali, também o professor, que tem a experiência de uma vida inteira com o contexto escolar, vê certos procedimentos rotineiros como as sombras da caverna de Platão - porque sempre estiveram ali, todos estão por demais acostumados a olhá-las, de modo mesmo a não conseguir mais vê-las. Tais rotinas, como a aula de exercícios, foram "naturalizadas" como um acontecimento típico e inquestionável do contexto escolar. Por isso, muitas vezes nem constam explicitamente em um plano de aulas - como no caso da PLA, no exemplo anterior - pois são óbvias; e todo professor tem a perigosa e invencível tendência de perpetuá-las, mesmo sem clareza de que serviço elas prestam ao aprendizado e que outro poderiam obstruir.

O formador faz, junto a PLA, uma série de perguntas em relação à situação vivenciada por ela, na intenção de possibilitar passagem do nível descritivo do fenômeno para o nível interpretativo. Esse procedimento pode ser visto sob o referencial das estratégias reflexivas de formação (ALARCÃO, 1996), em que confrontos são transformados em potenciais de reconstrução do conhecimento.

O confronto, no entanto, precisava ser criado, para que PLA enxergasse as "sombras". Nesse episódio, foi a própria professora quem iniciou o processo, pois soube relatar que a aula a incomodara. O formador aproveitou a oportunidade e potencializou-a através do questionamento inicial. Em outras situações, o professor não sentiria o incômodo, ou então conseguiria apontar apenas para algum sintoma de segunda ordem. Nesse caso, o formador precisou direcionar a atenção do professor para tal rotina ou pensamento.

Ao relatar e analisar a sua aula de exercícios, PLA trouxe à consciência um problema que a incomodava-e, pelo seu depoimento, percebe-se que o problema era recorrente ("sempre que eu resolvo na 
lousa, eu não me sinto muito bem"). O formador ajudou-a primeiramente a caracterizar a aula que fez ("mas o que é corrigir exercício?") e, em seguida, a procurar descobrir em quê tal atividade colaborava para os objetivos de seu planejamento.

PLA sentiu visível necessidade de expor seus incômodos com a aula de exercícios em outras situações e conseguiu, com isso, detalhar mais o problema e identificar a origem do seu incômodo ("ele pode até repetir sem saber o que está fazendo, e não é isso o que eu quero"). O papel do formador durante o episódio poderia ser comparado à figura que Schön (2000) denomina de "coach", o orientador que ouve o aprendiz ajudando-o a compreender mais profundamente o problema trazido, e conduz a reflexão no sentido de encontrar encaminhamentos para solucioná-lo.

A participação dos demais membros do grupo foi discreta, mas, ao que tudo indica, relevante no auxílio a PLA. Enquanto KAP corrobora o pensamento inicial de PLA, de que aula de exercícios não produz aprendizado, o monitor NA dá um exemplo pessoal que contrapõe essa ideia, conseguindo arrancar de PLA a interjeição "ah! Então deu certo pra vocế?".

Quando modificou seu planejamento incluindo a aula de exercícios, PLA não agiu de forma autônoma (" $n a$ outra aula eles queriam que eu corrigisse"). Pode-se avaliar que a discussão caminhou no intuito de proporcionar maior autonomia às suas escolhas futuras, ao menos no que toca essa estratégia de aula. A ação principal do formador foi incentivá-la a buscar um significado para a atividade que pudesse ser vinculado aos objetivos do seu planejamento. Vemos aí uma conexão com a educação problematizadora de Paulo Freire (1996), em que um problema desencadeador, colocando o educando no centro de sua formação e adequadamente conduzido pelo educador, estimula um "movimento dinâmico, dialético, entre o fazerer e o pensar sobre o fazer" (op.cit., p.42) e mantém como objetivo mais amplo sempre o de proporcionar maior autonomia ao educando.

O problema aparente (Schön, 2000) - aquele trazido pelo professor em seu relato - não é um problema falso, ele é levado em conta como um problema de fato. Porém, é visto como um sintoma que possui origem mais profunda, que o formador, através de uma escuta qualificada do relato, consegue ajudar o professor a desvendar. $\mathrm{O}$ formador faz questionamentos ("O que você queria com a aula? Vamos ver se você consegue dar um significado"), estimulando o professor a pensar nas causas daquele problema manifesto.

Homem - Tenho a impressão de ser um cativo, mas não sei explicar por que tenho tal impressão. 
Gorila - Anos atrás, muitos jovens deste país tiveram a mesma impressão. Fizeram um esforço ingênuo e desorganizado de escapar do cativeiro, mas acabaram fracassando, porque não foram capazes de encontrar as grades da jaula. Se você não descobre o que o está prendendo, a vontade de sair logo se torna confusa e ineficaz. (QUINN, 1998, p.27)

Pensando no desenvolvimento da autonomia da professora, as "grades da jaula" que a estavam prendendo a um procedimento que a incomodava, mas do qual não conseguia escapar, eram justamente a sua falta de clareza sobre como tal procedimento se conectava a seus objetivos amplos, bem como à sua "nova" concepção de ensino. A reflexão que ela engendrou, junto ao formador e aos pares no programa, foi atentamente acompanhada por todos os demais participantes, que assumiram como seu o problema em discussão, pois provavelmente tal procedimento também era utilizado em suas aulas.

Sobre essa forma de encaminhamento de uma discussão acerca do planejamento, vejamos como o formador encaminhou outro problema manifesto, em outro episódio. Neste, a professora CLO estava enfrentando um dilema com respeito a uma avaliação, quanto aos critérios que deveria usar na correção da prova, após ter examinado que os alunos em geral não foram bem. A mesmo tempo, CLO relata que está frustrada com os resultados, porque os alunos trabalharam muito nas aulas e ela acreditava que eles seriam capazes de produzir mais do que ficou evidente pelos resultados da prova. Sem desconsiderar o problema trazido pela professora, o formador propõe olhá-lo sob outro prisma:

F - Quando você diz, "eles são capazes de produzir coisas melhores do que eles produziram”. Então, eu acho que aí a reflexão que você está fazendo e a tua análise toda, é "o que é que eu estou avaliando quando eu dou esta prova?", né, e você já está percebendo que a tua avaliação vai ter um resultado ruim. (...) Agora por outro lado, você fala de uma série de coisas que você considera positivas - então, que os alunos participaram. Precisaria definir um pouco e tornar mais objetivo o que é essa participação.

Ou seja, o formador quer perguntar, o que a participacão dos alunos nas atividades do semestre auxiliou para a construção do conbecimento deles? CLO não havia identificado, anteriormente, incômodo algum em seu planejamento - a não ser pelos resultados da prova. O formador precisou auxiliá-la a ver o que era inicialmente tão evidente quanto despercebido pela professora.

A partir da colocação do formador, CLO traz outro problema, irmão daquele anterior: a atribuição de notas aos alunos pela participação nas atividades está mascarando os resultados reais de aprendizagem: 
CLO - Prof $f^{a}$, mas tem um detalhe também interessante, porque - o que eu percebo, conversando com a professora de matemática da escola, porque ela me falou a mesma coisa, "Ah, o pessoal não vai bem na prova, só que a gente leva em consideração outros trabalhos que eles fazem, a presença, e eles acabam tirando média”. (...) Então eles nunca estudam para a prova. Eles não estudam, porque eles sabem que vão tirar média.

O formador toma essa constatação como oportunidade para chegar a outro problema, mais profundo, que guarda conexões com o planejamento da professora e que, portanto, está dentro do seu limite de autonomia - o da pouca exigência de rigor nas atividades-meio, a partir das quais é atribuída a nota de participação.

F - Então, talvez, naqueles trabalhos que você está fazendo com eles, que eles estão produzindo, talvez aí esteja faltando a tua exigência de objetividade. Quer dizer, quando você fala pra eles, "vocês vão montar o abajur, vocês vão trazer o abajur", o trazer o abajur e fazer ele funcionar não vai ser objeto de uma nota se ele não fizer um relato preciso, com informações precisas, respeitando códigos de informação, etc. que são mais ligados ao conhecimento objetivo, ao conhecimento específico que você quer. (...) Não é que você vai deixar de premiar o sujeito ou de valorizar uma coisa que ele fez. Mas ele fez essa coisa e ele tem que dar a mais. (...) Certamente falta essa passagem da coisa mais qualitativa, espontânea, pra um rigor.

Embora tenha começado com uma discussão sobre avaliação, a qualidade do problema manifesto ("os alunos foram mal, como eu atribuo notas?') encaminhou o episódio para um desfecho com orientações e reflexões a respeito do planejamento.

Essa passagem do problema manifesto para o problema de fato (como propõe Schön), é feita através de uma análise aprofundada da situação e de seus determinantes, sempre pensando em soluções que o professor seja capaz de engendrar.

O caminho utilizado pelo formador foi de fazer o professor falar, o professor produzir um problema ou incômodo. A identificação da origem do problema, que ocorreria em seguida, seria uma tarefa conjunta e que procuraria mudar o foco para analisar o próprio paradigma de ensino que alicerça as atividades constantes em um plano de ensino e a maneira de conduzi-las em classe.

O conceito de paradigma pode ser de boa ajuda para compreendermos as ações do formador. O professor olha para um objeto pertencente ao mundo (uma prova escrita ou uma aula de exercícios) com os filtros do seu próprio paradigma ${ }^{3}$. Em todos os episódios, constatamos que os professores olham para as situações profissionais com as quais se defrontam utilizando uma visão mais relacionada ao ensino transmissivo, a uma epistemologia da 
ciência empírico-indutivista e a uma concepção de aprendizagem por aquisição conceitual (SANTOS, 2005). Por conseguinte, interpretam uma aula, uma dúvida de aluno ou um resultado de prova de acordo com esses pressupostos.

Esse paradigma não pode ser substituído por meio de uma simples verbalização ou comunicação. A visão "tradicional" de escola, transmissiva, é repetidamente apresentada, de várias maneiras, em vários contextos do cotidiano. Mais do que apresentada, essa visão é vivida pelos sujeitos desde seus primeiros anos escolares e, na maioria das vezes (senão em todas), é revivida também nos bancos universitários. Dessa forma, uma comunicação verbal será muito mais pobre que toda a coleção de informações e vivências que o sujeito teve. Além disso, como os paradigmas não são aprendidos na forma de uma explicação ou definição, eles geralmente são inconscientes. As marcas do paradigma aparecem na ação do sujeito, mas este é incapaz de verbalizá-lo, ou mesmo identificálo como determinante da ação. Por isso talvez, nos dois episódios exemplificados, a identificação das marcas do paradigma nas ações das professoras tenha partido do elemento assimétrico - o formador, sendo inicialmente invisíveis por elas próprias. No entanto, a prática da identificação de tais marcas é aprendida pelos participantes do grupo, conforme a vivenciam nas ações do formador. Professores que estavam há mais tempo participando desse programa eram capazes de ouvir os relatos dos colegas e fazer a (singela, porém extremamente incisiva) pergunta-chave - "Onde você queria chegar com essa aula? Qual era o seu objetivo?”

Os paradigmas só passam a ser comunicáveis entre aqueles que adquirem consciência sobre eles. Por isso, a mediação verbal pura - descolada de vivências concretas - não é tão útil para promover mudanças estruturais em um conjunto de ações.

Para ver o mesmo objeto sob outro prisma (i.e. com os filtros de outro paradigma), a verbalização deve se referenciar a situações vividas, concretas. Como proporcionar tais oportunidades? Nesse programa, identificamos duas possibilidades de ocorrência:

- fazer uma comparação. Essa ação é possível quando o sujeito tem alguma vivência em outro paradigma. Então o formador recorre a ela apelando para a memória da situação vivida, sob a forma "você se lembra quando fizemos aquela atividade, e você teve essa dívida...?" O formador precisa saber que essa memória existe - ou seja, ele deve ter compartilhado a situação. Por isso, supomos, essa ação foi rara no grupo que acompanhamos, e aconteceu em apenas 
um episódio, dos mais de 30 analisados.

- pontuar e identificar as marcas do paradigma no objeto, da forma como é visto pelo professor, e perguntar como aquelas mesmas marcas poderiam ser interpretadas usando-se o (novo) paradigma em construção. Isso foi o que o formador deste programa fez, na maioria dos episódios analisados. Salienta-se que o esforço para modificar o olhar tem que ser feito pelo professor aprendir, para que o aprendizado seja possível. Como em analogia com a Figura 1 a seguir, do pato-coelho:

FIGURA 1

Pato/coelho

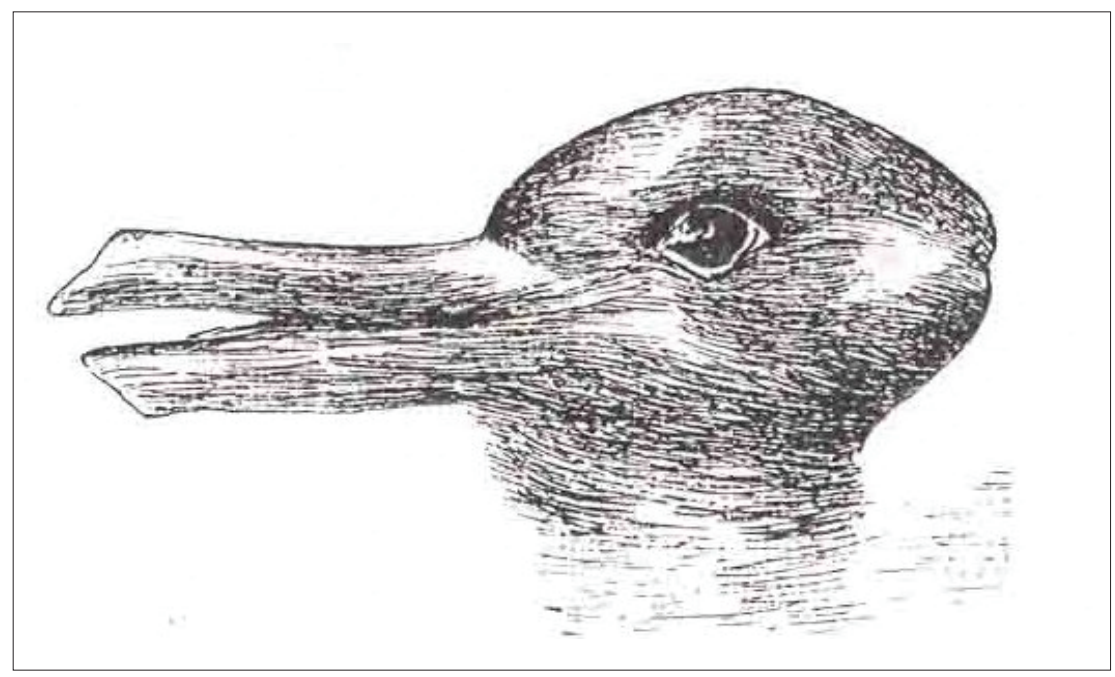

Fonte: Wikipedia ${ }^{4}$

Imagine que o observador esteja enxergando somente o pato. O formador quer que ele enxergue o coelho, então diz " $A$ h, você está vendo um pato? Mas olha como esse bico poderia ser interpretado como orelha..." Para surtir efeito, o observador tem que conseguir, ele mesmo, ver a orelha. Qualquer conjectura sobre a figura do coelho só terá significado depois que o observador enxergar o coelho. Enquanto ele só vê o pato, toda explicação que parta do pressuposto da existência do coelho lhe será incompreensível.

No paradigma transmissivo, as atividades que o aluno realiza, quando não são pensadas unicamente para despertar o interesse, servem para "fixação" de um conceito, e não para a sua construção pois o conceito é transmitido pelo discurso do professor. Assim, não se vê como necessária uma conexão entre as atividades formando 
um eixo que aponte para um objetivo. O professor pode inseri-las "aleatoriamente" para preencher as aulas. Assim, quando o programa de desenvolvimento profissional proporciona uma "biblioteca" de novas atividades que o professor pode utilizar para trabalhar os conceitos, o professor entusiasmado tende a inseri-las no seu plano de ensino, empreendendo modificações no plano que nem sempre são justificáveis do ponto de vista do aprendizado que se almeja. Por exemplo, nesse curto diálogo entre o formador e a professora KAP:

\footnotetext{
F - Não, mas aí é que está, você tem que ver por que você acha aquilo importante e o que o teu objetivo na verdade está exigindo (...), e se isso tem ligação. (...) “eu achei que isso é bonito, mas será que é oportuno? Será que está no lugar certo?” Eu vejo, que (...) [o experimento da lei de Ohm, que a gente fez a semana passada] todo mundo gostou, né? Não foi bonitinho? Não deu uma vontade louca de levar e fazer na classe? Aposto que alguém até fez.

KAP - [encabulada] Eu não fiz ainda...

F - Pois é, "não fiz ainda", né, "mas vou fazer". Então, agora, e aí? Será que não vale à pena parar pra pensar? O que é que eu estou fazendo quando eu estou levando isso, nesse momento, nessa situação? O que eu estou fazendo com isso? Então tem essa coisa que às vezes a gente esquece - facilmente a gente desgruda do planejamento.
}

Esse curto diálogo aconteceu no meio de outro episódio, que discutia uma aula da professora PLA. O formador fez o alerta, mas o aprendizado, de fato, só ocorre conforme o professor tem a oportunidade de analisar os resultados de aprendizagem e a evolução conceitual dos alunos nas aulas - afinal, para ele, este é o critério: ele está interessado no aprendizado do aluno e é quando esse aprendizado não ocorre que ele se dispõe a modificar seu plano de ensino.

\section{CONCLUSÕES}

O trabalho do programa com o planejamento pedagógico procurou discutir com o professor suas aulas planejadas, subsidiando-o com atividades que poderia usar para trabalhar aqueles tópicos que planejou, porém, mais que isso, ajudou o professor a revisar constantemente seus planos de ensino com base no que ele traria como constatação da realidade vivenciada em sua sala de aula com seus alunos.

A emergência de uma questão que poria o planejamento em discussão foi proporcionada, sobretudo, por relatos de aulas de professores. O formador trabalhou de forma situada na prática docente, partindo do problema concreto e envolvendo-se com esse 
problema. Por isso, todos os episódios de formação têm como protagonista um professor-aprendiz - aquele que relatou sua aula e os participantes todos acompanham o diálogo estabelecido com esse professor. O caminho, portanto, foi do concreto para o abstrato e da prática real para sua análise e reflexão.

Dentre os obstáculos mais usuais que os programas de formação continuada encontram ao ensinar uma nova forma de planejar o ensino estão: i) o professor aplica o plano de ensino comunicado pelo programa, mantendo objetivos e/ou atitudes diferentes das que embasam aquele plano, e com isso, obtém resultados frustrantes. Com isso, conclui que o plano não se adéqua à sua realidade e contexto escolar específico; ii) o professor se recusa a aplicar o plano, seja por se sentir inseguro ou por não compreendê-lo. Em ambas as situações, o obstáculo subjacente é de natureza primordialmente epistemológica - ou seja, o professor se mantém em uma epistemologia empírico-indutivista, embasando um ensino transmissivo, que entra em contradição com o plano de ensino proposto. Porém, como tal obstáculo não é evidenciado ao professor, este aponta para outros motivos, extrínsecos à sua prática, para justificar o fracasso. Assim, em vez de o planejamento estar no foco das reflexões, estas versam sobre as condições externas à atuação docente.

Neste programa que analisamos, os obstáculos foram também de natureza primordialmente epistemológica. No entanto, o programa estruturou-se de forma que tanto o plano de ensino quanto as modificações desse plano proviessem do próprio professor, e também de forma que a avaliação do plano posto em prática tomasse como embasamento empírico os resultados, seja em termos de aprendizagem dos alunos, seja em termos da percepção do professor quanto à pertinência e importância das atividades realizadas. Essa opção didática do programa oportunizou o aprofundamento das reflexões, de modo que o obstáculo epistemológico viesse à tona e pudesse ser adequadamente enfocado, especialmente para que o professor o visse como significativo.

Uma característica peculiar deste programa foi partir da prática concreta do professor - ou seja, o programa conseguiu concretizar uma recomendação já não tão atual da literatura em formação docente: nãopartir de uma ideia pronta a ser "aplicada", fomentando a ação autônoma e a reflexão sobre a prática. Os professores determinaram os pontos de partida para a sua formação quando relataram suas aulas. A partir daí, uma das habilidades essenciais do formador foi saber, partindo dos saberes iniciais do grupo em formação, não "estacionar" neles - 
ou seja, construir um caminho em direção aos objetivos do programa. Esse caminho pode ser sintetizado por:

\section{FIGURA 2}

Esquema das fases do ensino, no programa de formação

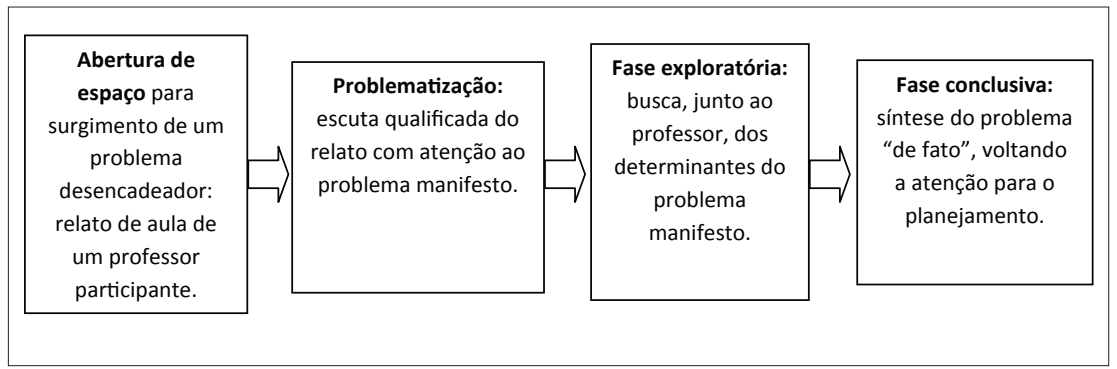

Fonte: figura elaborada pelas autoras.

No início do episódio, no que poderíamos chamar de fase introdutória, o formador parte de um relato de aula em que um professor traz o seu problema ao grupo. Esta é a fase da queixa, em que um problema manifesto aparece. A característica mais marcante dessa fase é a escuta qualificada do formador, que consegue problematizar a situação vivida pelo professor, direcionando a atenção de todos para o problema manifesto.

Com o problema adequadamente formulado, inicia-se a segunda fase, que podemos chamar de exploratória ou interpretativa, na qual formador e participantes procuram os determinantes implícitos da situação relatada, porém ainda sem buscar por soluções. A característica marcante dessa fase é a atitude não diretiva. São fornecidos novos elementos contextuais e entram também elementos teóricos que auxiliam na interpretação da situação relatada, de modo que a análise possa estabelecer conexão com o plano de ensino. A conclusão dessa fase acontece quando se compreende o problema "de fato", ou seja, a origem conceitual/epistemológica do problema manifesto.

A última fase (conclusiva) trata proativamente das possibilidades de ação do professor, dentro dos determinantes contextuais analisados nas fases anteriores. Nesta, o formador retoma as colocações das fases anteriores do diálogo e sintetiza o problema "de fato", relacionando-o com o problema manifesto e com modificações possíveis no plano de ensino. A característica marcante dessa fase é o foco, ou seja, a habilidade de não se perder no pitoresco da situação relatada ou de permanecer em seus condicionantes externos, sobre os quais o encaminhamento independe de uma ação do professor. $\mathrm{O}$ desfecho, isto é, a conclusão do ponto de ensino é feita pelo formador, após a discussão ter 
levantado alguns pontos que ele considerou necessários para que uma sistematização pudesse ser compreendida.

A coesão do grupo - ou seja, o fato de que todos os professores ouviam e participavam atentamente de um problema que inicialmente era particular, de um deles - foi proporcionada em parte pela forma de condução das reuniões, e em parte pelo contexto específico comum: todos os professores lecionavam física na escola pública, e todos os planos de ensino versavam sobre o conteúdo de eletromagnetismo. Com o contexto adequadamente delimitado, os problemas que um enfrenta são verossímeis e significativos para os demais. Dessa forma, as questões que surgiam no depoimento de um dos professores (por exemplo, de como começar a ensinar a eletrodinâmica; em que momento do meu plano de ensino introduzir a lei de Ohm, fazer pilha de Daniell ou a de Volta, fazer como demonstração ou como atividade experimental, com que objetivo fazer aulas com circuitos complexos) eram imediatamente assumidas por todos, que aproveitavam a discussão para reavaliar seus planos de ensino.

\section{CONSIDERACְÕES ADICIONAIS}

O formador deste programa analisado procurou agir em coerência com a concepção de ensino a ser partilhada com os professores participantes: trabalhou a partir da prática docente de cada professor, iniciou os episódios de ensino pela atitude de ouvir o professor e manteve suas ações coerentes com a prática pedagógica que desejava ensinar. Percebemos que nenhum desses pontos é novidade na literatura sobre a formação docente, mas são raramente encontrados como prática na formação. O que ocorre? Quais são as barreiras entre o que sabemos e o que somos capazes de fazer?

A pesquisa não nos fornece elementos para esta resposta, mas não seria irracional elaborarmos a hipótese de que pode haver um paralelo entre as dificuldades que os professores enfrentam para modificar suas práticas e as que os formadores dos professores enfrentam, ao elaborar seu plano de formação. É plausível imaginar que os formadores de professores possam, eventualmente, compartilhar do mesmo paradigma transmissivo: se queremos fazer uma formação de professores, diagnosticamos suas deficiências e planejamos cursos, nos quais lhes ensinaremos o que não sabem. Essa parece-nos a ação sensata e correta. Ensinar é, de certa forma, visto como falar - se vou ensinar algo a você, vou esclarecê-lo sobre o que é correto. Ou então vou ouvi-lo, para diagnosticar o que você não sabe - para depois saber 
o que preciso lhe falar. Ouvir o professor, essa escuta qualificada que observamos no programa analisado, é uma ação muito difícil.

$\mathrm{Na}$ visão mais comum no nosso meio, o conhecimento pertence ao mundo das ideias, ele é, portanto, teórico e abstrato. A ação é a aplicação desse conhecimento no mundo - ela não é um conhecimento em si. Se o sujeito possui o conhecimento, ele saberá derivar dele a ação correta. A prática do ensino transmissivo atende muito bem a essa forma de conceber o conhecimento, pois basta clarear o intelecto que a ação o acompanhará. Daí a dicotomia entre a teoria e a prática.

Por conseguinte, os conhecimentos que produzimos em educação são majoritariamente proposicionais - "devemos ser construtivistas", "devemos ouvir o aluno", "devemos partir do conhecimento do aluno", "devemos saber tratar as diferenças"... Achamos que o como fazer é imediatamente derivado do que fazer. Porque acreditamos que verdadeiramente seremos capazes de ensinar o conhecimento prático através do verbo. Falamos, exemplificamos, frisamos e esperamos que pelo esclarecimento racional do sujeito a sua ação se modifique.

Por isso a pedagogia construtivista é difícil. Não sabemos conduzir um aprendizado sem começar com um esclarecimento racional de um conhecimento já generalizado e abstrato; nossas metodologias de ensino são proposicionais, verbais, essencialmente pertencentes ao mundo das ideias. Essas metodologias servem muito bem para ensinar o conhecimento teórico, mas não funcionam adequadamente para o conhecimento prático - a não ser que o aprendir já tenha uma vivência no outro paradigma, que prevê a possibilidade daquele outro tipo de ação.

É comum os professores das universidades ensinarem o construtivismo aos licenciandos através de aulas caracteristicamente transmissivas. A incoerência entre o saber e o fazer, entre a teoria e a prática, é possível dentro de um paradigma dicotômico, pois os elementos não precisam estar conectados. Na cultura indiana talvez se dissesse: se você não sabe fažer, você não sabe. Nós, muitas vezes, achamos que é possível ensinar mesmo sem saber fazer.

O que significa, afinal, ouvir o professor e trabalhar a partir de sua prática? Em que essa "escuta qualificada" do formador é uma habilidade profissional, diferente da escuta cotidiana? Antes de tudo, implica assumir uma disposição inicial de acreditar que o professor tem uma competência para o que faz; portanto, começa por uma atitude de profundo respeito àquele profissional que está participando do programa de formação. Em seguida, ao ouvir um relato, buscar os determinantes implícitos daquela prática - que não serão apenas racionais: são também emocionais, ideológicos, paradigmáticos. Para 
compreendê-los, é necessária uma escuta interessada e completa, por alguém experiente e conhecedor da área, além de disposto a auxiliar o professor no que ele precisa para concretizar suas intenções. Também é oportuno conhecer a pessoa do professor. Segundo a expressão de Patto (1990, p.352), o formador “[...]deve estar capacitado para uma escuta que, criticamente informada, leve em conta as fantasias, angústias e defesas que acompanham qualquer processo de mudança."

Ouvir o professor e partir da sua prática docente é também criar um compromisso com suas aulas, com os problemas que surgem e as novidades encontradas. É também comprometerse com seu desenvolvimento profissional. "Comprometer" é um pouco mais que "prometer" - exige a promessa das duas partes; nem o professor está sozinho, nem o formador é detentor de toda ação. Realizar um programa de desenvolvimento profissional é de fato muito diferente de realizar um treinamento ou capacitação. Não se trata apenas de uma atualização dos termos.

Um professor bem "treinado" não é exatamente o que queremos para melhorar a educação brasileira. Vemos que é necessário um profissional flexível, que saiba trabalhar as diferenças, avaliar planos de ensino, adequar atividades e educar para a cidadania. Também queremos professores talentosos e criativos e que saibam escolher, no seu acervo pedagógico, os melhores elementos para trabalhar com a diversidade de situações concretas que encontram em sua prática. Estas todas são qualidades não técnicas, portanto, treinamentos não funcionam para ensiná-las. Precisamos, de fato, de um programa de desenvolvimento profissional - que conceba seus participantes como profissionais, responsáveis pelo trabalho que fazem e potencialmente autônomos para tomar decisões e operar modificações nas suas práticas, nos seus procedimentos ou nos seus planos de ensino... E que têm o que falar, o que contribuir, dentro do programa.

\section{REFERÊNCIAS}

ALARCÃO, I. (org.). Formação reflexiva de professores: estratégias de supervisão. Portugal: Porto Ed., 1996.

ANDERSON, J. R. Cognitive psychology and its implications. New York: W.H. Freeman and Company, 1990.

AVALOS, B. CPD policies in the Latin American Region. In: DAY,C; SACHS, J (Orgs.) International handbook on the continuing professional development of teachers. Maidenhead: Birks, Open University Press, 2004. p. 119-145.

BEJARANO, N. R. R.; CARVALHO, A. M. P. A história de Eli: um professor de física no 
início de carreira. Rev. Bras. Ens. Fis. v. 26 n.2, p. 165-178, 2004.

BRASIL. Conselho Nacional de Educação. Resolução CNE/CP nº1, de 18 de fevereiro de 2002. BRICKHOUSE, N. W. Teachers' content knowledge about the nature of science and its relationship to classroom practice. Paper presented at the Annual Meeting of the American Educational Research Association, San Francisco, CA, mar. 27-31, 1989. Disponível em: <http://eric.ed.gov/ERICDocs/data / ericdocs2sql/content_storage_01/ 0000019b/80/1e/98/e0.pdf>. Acesso em: 06.jul.2010

CAMARGO, S.; NARDI, R. A formação inicial de professores de física: discursos de licenciandos sobre a prática docente. Enseñanz̧a de las ciencias, nº extra - VII congresso, 2005.

CONTRERAS, J. A autonomia de professores. São Paulo: Cortez, 2002.

DAY, C.; SACHS, J. Professionalism, performativity and empowerment: discourses in the politics and purposes of continuing professional development. In: DAY, C.; SACHS, J (Orgs.) International handbook on the continuing professional development of teachers. Maidenhead: Birks, Open University Press, 2004. p. 3-32.

FÁVERO, M. L.A. Universidade e estágio curricular: subsídios para discussão. In: ALVES, N. (org.). Formação de professores: pensar e fazer. SP: Cortez, 1993. p. 53-71.

FREIRE, P. Pedagogia da autonomia: saberes necessários à prática educativa. São Paulo: Paz e Terra, 1996. FUSARI, J. C. O planejamento do trabalho pedagógico: algumas indagações e tentativas de respostas. Série Ideias, v. 8, p. 44-53, 1990.

GRUNDY, S.; ROBISON, J. Teacher professional development: themes and trends, in the recent Australian experience. In: C. Day e J. Sachs (Org.) International handbook on the continuing professional development of teachers. Maidenhead: Birks, Open University Press, 2004. p. 146-166.

GURIDI, V. M. A inclusão de professores de ensino básico na pesquisa: um desafio institucional. 2007. 217 f. Tese (Doutorado em Educação) - Curso de Pós-Graduação em Educação da Universidade de São Paulo, São Paulo. 2007.

LÜDKE, M.; BOING, L. A. Do trabalho à formação de professores. Cadernos de Pesquisa, UFMG, v. 42, n.146, p. 428-451, 2012.

LÜDKE, M. ; ANDRÉ, M. E. D.A. Pesquisa em educação: abordagens qualitativas. São Paulo: E.P.U., 1986.

MALDANER, O. A. A formação inicial e continuada de professores de química. Ijuí: Ed. Unijuí, 2006.

PACCA, J. L. A. O Profissional da Educação e o Significado do Planejamento Escolar: Problemas dos Programas de Atualização. Revista Brasileira de Ensino de Física Vol. 14 (1), p. $39-44,1992$.

PATTO, M. H. S. A producão do fracasso escolar: histórias de submissão e rebeldia. São Paulo: Queiroz, 1990.

PIMENTA, S. G. Professor reflexivo: construindo uma crítica. In: PIMENTA, S.G.; GHEDIN, E. (orgs.). Professor reflexivo no Brasil: gênese e crítica de um conceito. São Paulo: Cortez, 2002, p.12-52.

PLATÃO. A República. Tradução de Anna Lia Amaral de Almeida Prado. São Paulo: Martins Fontes, 2006.

QUINN, D. Ismael: um romance da condição humana. São Paulo: Peirópolis, 1998.

SANTOS, M. E. V. M. dos. Que educação? Lisboa: Santos Edu, 2005.

SAVIANI, D. Formação de professores: aspectos históricos e teóricos do problema no contexto brasileiro. Revista Brasileira de Educação, Rio de Janeiro, v. 14 n.40, p.143-155, 2009. 
SCARINCI, A. L. Tirando o coelho da cartola - a atuação do formador em um programa de desenvolvimento profissional docente. 2010. 230 f. Tese (doutorado em educação) - Programa de pós-graduação em Educação da Universidade de São Paulo. São Paulo, FE-USP, 2010.

SCARINCI, A. L. ; PACCA, J. L. A. O professor de Física em sala de aula: um instrumento para caracterizar sua atuação. Investigações em Ensino de Ciências, v. 14, p. 457-277, 2009.

SCARINCI, A. L. Uma proposta para caracterizar a atuação do professor na sala de aula. 2006. $158 \mathrm{fl}$. Dissertação (mestrado em ensino de ciências) - Programa de pós-graduação Interunidades em Ensino de Ciências da Universidade de São Paulo. São Paulo: USP, 2006.

SCHÖN, D. Educando o profissional reflexivo: um novo design para o ensino e a aprendizagem. Porto Alegre: Artmed, 2000.

SILVA, A. M. Formação contínua de professores, construção de identidades e desenvolvimento profissional. In: MOREIRA, A. F.; MACEDO, E. F. (Orgs.). Currículo, Práticas Pedagógicas e Identidades. Porto: Porto Editora, 2002. p.119-137.

SILVA, E. L. Ensinando e aprendendo em um programa de formação contínua: reflexos de um trabalho coletivo. 2009. 247 f. Tese (Doutorado em Educação) - Curso de Pós-Graduação em Educação da Universidade de São Paulo, São Paulo. 2009.

STENHOUSE, L. Investigación y desarrollo del curriculum. Madrid: Morata, 1984.

VIEIRA, F. Alunos autônomos e professores reflexivos. In: TAVARES J. (org.) Para intervir em Educação. Portugal: Ed. CIDInE, 1994, p.331-339.

ZEICHNER, K. El maestro como profesional reflexivo. Cuadernos de Pedagogia, Espanha: Barcelona, n. 220, p. 44-49, 1992.

\section{NOTAS}

${ }^{1}$ Conferência de título "Pedagogia: a Terceira Margem do Rio", proferida na Faculdade de Educação da USP em 20 de maio de 2011. Disponível em: www.iea.usp.br/pesquisa/ conferencistas-internacionais/antonio-novoa (acesso em 26.maio.2015).

${ }^{2} \mathrm{Nas}$ transcrições, usamos sublinhado para falas mais pausadas e negrito para trechos com tom de voz mais forte. Fala entre parênteses indica que o interlocutor falou ao mesmo tempo que outro.

${ }^{3}$ Utilizamos "paradigma" num sentido mais análogo ao kuhniano; de visão de mundo ou pressuposto filosófico partilhado pelos membros de uma comunidade.

${ }^{4}$ Disponível em: http://en.wikipedia.org/wiki/Philosophical_Investigations

Recebido: 15/07/2013

Aprovado: 02/03/2015

Contato:

USP - Instituto de Física

Rua do Matão, Travessa R, 187. Edifício Principal

Ala II. Sala 325 - Cidade Universitária

São Paulo $|\mathrm{SP}|$ Brasil

CEP 05.508-090 
